\title{
REGIME INTERNACIONAL DE MUDANÇAS CLIMÁTICAS E SEGURANÇA ENERGÉTICA
}

\author{
Cynthia Danielle Siqueira
}

\begin{abstract}
Resumo
0 presente artigo se propõe demonstrar a pertinência da cooperação, via regimes, como possibilidade plausível para lidar com problemas vinculados a segurança no setor energético, em detrimento ao uso da força e ações isoladas dos atores estatais no ambiente internacional. Propõe-se ainda centrar as atenções em um determinado regime internacional: o de mudanças climáticas. Esta escolha se dá pela percepção de que tal fenômeno pode influenciar na geração e intensificação de problemas relacionados ao acesso, uso e distribuição de energia e suas implicações políticas, econômicas, sociais e ambientais. Para tanto, será considerado, em linhas gerais, o contexto internacional e as demandas energéticas a serem tratadas pelo regime e como este lida com tais demandas em sua produção normativa.
\end{abstract}

Palavras-chave: Mudanças climáticas. Regimes internacionais. Segurança energética.

\section{INTERNATIONAL REGIME OF CLIMATE CHANGE AND ENERGY SECURITY \\ Abstract}

This article aims to demonstrate the relevance of cooperation through International Regimes as a reasonable possibility of dealing with problems related to security in the energy sector over the use of force and isolated actions of state in the international environment. It is also proposed to focus the attention on a particular international regime, namely, that of climate changes. This choice relies on the perception that such phenomenon can influence the generation and intensification of problems related to access, use and distribution of energy as well

\footnotetext{
${ }^{1}$ Doutoranda em Alterações Climáticas e Políticas de Desenvolvimento Sustentável. Universidade Técnica de Lisboa, Portugal. profissional82@gmail.com
} 
as its political, economic, social and environmental effects. It will be considered, the international context and the energy demands to be treated by the regime and how it deals with such demands in its legislation.

Keywords: Climate change. International regimes. Energy security.

\section{INTRODUÇÃO}

0 impacto presente e futuro das mudanças climáticas em todo o globo e seus reflexos nas questões energéticas está cada vez mais presente no debate de segurança, demandando atenção crescente dos diversos atores que atuam nos diferentes níveis de análise, do global ao local. À luz de tal fenômeno ambiental, observa-se a opção por saídas institucionais no âmbito internacional que buscam soluções conjuntas, principalmente dos atores estatais, para fazer frente a um problema que se materializa na agenda de segurança. 0 recurso a um instrumento cooperativo, em detrimento de ações isoladas e auto-interessadas no jogo de poder do sistema internacional, demonstra viabilidade na resolução de problemas de segurança energética.

Ao se pensar a cooperação internacional em matéria energética, no contexto contemporâneo, é importante discutir o papel desempenhado pelos regimes como espaços de conformação política em ações coordenadas para a consecução de interesses comuns em torno da resolução de problemas em áreas específicas. A dinâmica envolvendo as várias fases do regime possibilita entender as influências simultâneas de interesses diversos, incluindo os atores tanto no nível doméstico como no nível internacional.

0 estudo a seguir se inicia com a análise téorica sobre o papel dos regimes na cooperação internacional. Parte para uma breve correlação entre mudanças climáticas e segurança energética e para as considerações sobre a estrutura do Regime Internacional de Mudanças Climáticas, as demandas e as implicações energéticas nele contidos.

\section{INSTITUIÇÕES INTERNACIONAIS: REGIMES}

Quando os agentes estatais decidem adotar a cooperação como estratégia, instituições internacionais são formadas para promover o ajuste e a coordenação de políticas, assim como paraestimularum comportamentodos agentescomprometidos com a efetivação das diretrizes negociadas. Nesta perspectiva, as instituições podem 
ser pensadas como estruturas que viabilizam a cooperação na busca pela solução de problemas de ação coletiva e da promoção de benefícios coletivos. Segundo a abordagem institucionalista, as instituições podem promover a cooperação ao dar certa margem de segurança e previsibilidade, ao facilitarem o acesso à informação compartilhada e ao constrangerem o comportamento dos atores. A idéia de que as instituições são instrumentais à cooperação por possibilitarem maior grau de previsibilidade e regularidade às ações de atores racionais é trabalhada por diversos teóricos, através de diferentes caminhos e conclusões.

Em termos de definição, as instituições podem ser compreendidas como agrupamento de regras formais e informais que, conectadas, prescrevem e constrangem o comportamento, definindo expectativas (KEOHANE, 1989). As instituições variam em múltiplas dimensões, incluindo tipos e números de membros, alcance funcional, domínio geográfico, grau de formalização e estágio de desenvolvimento (YOUNG, 1994). Quanto a sua tipologia, podem se configurar como convenções ${ }^{2}$ ou organizações internacionais ${ }^{3}$ e ainda como regimes.

0 conceito tradicional de regime é apresentado em 1975, sendo entendido como "um conjunto de expectativas mútuas, regras e regulamentos, energias organizacionais e compromissos financeiros que tenham sido aceites por um grupo de Estados" (RUGGIE apud KEOHANE, 1984, p. 56, tradução nossa). Krasner (1983, p. 2) também apresenta sua definição como "[...] Conjunto de princípios implícitos ou explícitos, normas, regras e procedimentos decisórios em torno do qual as expectativas do ator convergem em uma determinada área das relações internacionais" 4 (tradução nossa).

Keohane (1984) destaca que a formação de regimes internacionais não altera o sistema internacional, que se mantém pautado pela soberania dos Estados

\footnotetext{
${ }^{2}$ Convenções: caráter informal com regras e entendimentos implícitos para o incentivo da coordenação.

3 Organizações internacionais de caráter intergovernamental (OIG's) ou não-governamentais (OING’s): as primeira são desenhadas pelos Estados a partir de específicos fins. Possui uma estrutura burocratizada, com sede física, regras próprias (KEOHANE, 1989). Geralmente possuem personalidade legal (YOUNG, 1994). No caso das OING’'s diferenciam-se por não serem controladas pelos governos nacionais.

${ }^{4}$ Krasner (1983) aponta para a diferença entre regimes e acordos. Segundo ele, acordos se referem aos procedimentos de curto prazo visando um ajuste específico. Regimes visam facilitar acordos. Acordos estão relacionados com mudanças de comportamento que ocorrem quando há variação de interesses ou de relações de poder. Regimes vão além de ajustes temporários e tendem a criar padrões de comportamentos mais estáveis e de maior duração, pelo comprometimento dos atores com regras que constrangem a maximização de poder imediata de curto-prazo.
} 
e pelo comportamento auto-interessado. Entendendo que a criação de regimes depende de interesses convergentes, os incentivos para criá-los são maiores quando há maior concentração de problemas políticos. Desta forma, os regimes podem diminuir os custos que esses problemas geram e podem afetar os interesses, expectativas e valores dos atores. Através dos regimes a cooperação é mais eficiente. Então, uma vez que se verifica um aumento dessas áreas-problema, devido à crescente interdependência, a demanda por regimes também cresce.

As instituições internacionais podem atuar como espaço de cooperação nas questões de segurança, sejam elas referentes ao ambiente internacional e nacional numa perspectiva tradicional dos estudos de segurança, sejam elas direcionadas a temáticas "low politics", que se apresentam em problemas políticos com impacto em vários setores, numa lógica de interdependência. Nesse sentido, a questão energética, está presente não só nas atenções domésticas como também no ambiente internacional, sendo objeto de negociação dentro de diversas instituições internacionais 5 .

Nos estudos sobre regimesécomum considerar que o ambiente internacional é a esfera única de relevância nas negociações em torno da cooperação, já que é nela que se definem diretamente as ações coordenadas entre os agentes estatais. Entretanto, um regime necessita de implementação para atingir o seu fim e neste ponto se observa com mais clareza a importância dos fatores domésticos de cada Estado para viabilizar essa implementação. A diversidade e o jogo de interesses internos envolvidos se refletem no posicionamento do Estado frente às negociações internacionais e tais interesses reagem ao processo de barganha institucional em ambos os níveis: o doméstico e o internacional.

Nesse sentido, uma importante consideração a ser feita acerca dos regimes internacionais é o seu caráter dinâmico. Este fator está presente no trabalho de autores como Zartman (2003), no qual um regime vai além das regras, normas, princípios e padrões de conduta, aspectos que podem ser associados à ideia de rigidez. Pelo contrário, para o autor citado, um regime internacional é entendido como um processo contínuo de barganha política, envolvendo negociações

\footnotetext{
${ }^{5}$ A partir da década de 1960, observa-se o crescimento da demanda por instituições internacionais para lidar com os problemas de segurança, relacionados às questões energéticas. É o caso da criação da Agência Internacional de Energia Atômica (AIEA), Agência Internacional de Energia (AIE/IEA), assim como da realização e celebração de diversos tratados e convenções (tal como o Tratado sobre a Não-Proliferação de Armas Nucleares, assinado em 1968; ou a Convenção de Viena sobre Responsabilidade Civil por Danos Nucleares, de 1963).
} 
posteriores às iniciais, na medida em que se faça necessário para a governança do regime e de seus reajustes. Nessa pesquisa, parte-se da premissa da dinâmica do regime e da interação entre os níveis nacional e internacional.

As dinâmicas ${ }^{6}$ que envolvem os processos constitutivos e de adaptação do regime são complexas, pois não se excluem da influência de diversos atores, sejam eles estatais ou não estatais, nas diretrizes condutoras da instituição em tela, a partir dos interesses específicos de cada um dos envolvidos. Tanto os interesses domésticos influem no regime, a partir da posição dos Estados (que passaram por um processo interno de barganha e pressão política dos variados stakeholders), também por pressões externas ao regime (como a mídia e a opinião pública, assim como a ação de relevo da sociedade civil sobre pontos de discussão que se configura como elementos de pressões governamentais); como a própria condução e demanda do regime pode influir na esfera política doméstica. Há, portanto, uma influência simultânea entre os níveis doméstico e internacional que se verifica em cada caso e de acordo com os atores e contextos analisados.

Spector (2003) parte da dinâmica do regime para descrever importantes etapas que envolvem as negociações dentro de sua estrutura. Identifica duas etapas: as negociações iniciais, que ele denomina como anterior ao acordo (preagreement) e as negociações subseqüentes (post-agreement). Nas negociações iniciais a preocupação é quanto à identificação de acordos necessários e atores interessados. Concentra-se mais no estabelecimento de princípios e normas mais gerais que forneçam base para a formação do regime. Na fase post-agreement 0 foco é na implementação do estabelecido no acordo inicial, sua viabilidade, assim como no trato com atores sub-nacionais e não-governamentais. Entende-se essa fase como um processo dinâmico de promoção de diálogo em relação a questões não resolvidas no acordo inicial. Com base neste autor, consideram-se com mais precisão as fases de interação durante as negociações de um regime entre o nível doméstico e o nível internacional. Importante ressaltar que as fases não acontecem de forma hierárquica, mas podem acontecer concomitante e concorrentemente. São elas:

\footnotetext{
${ }^{6}$ Outro importante ponto a se destacar é que a dinâmica descrita não restringe o grau de previsibilidade e estabilidade que as instituições oferecem em face de outras medidas isoladas. Se instituições produzem maior grau de previsibilidade, tal previsibilidade está intimamente relacionada a alguns elementos que são mais duradouros - assim, o regime permite o processo político mais estável, exatamente porque esse processo está governado por normas e/ou regras.
} 


\section{Quadro 1 - Fases do Regime Internacional}

\begin{tabular}{|l|l|}
\hline \multicolumn{1}{|c|}{ PLANO INTERNACIONAL } & \multicolumn{1}{|c|}{ PLANO DOMÉSTICO } \\
\hline $\begin{array}{l}\text { Formação de Regime: esta fase compreende } \\
\text { as negociações para a fixação de normas } \\
\text { e processo de governança em uma } \\
\text { determinada área objeto de cooperação. }\end{array}$ & $\begin{array}{l}\text { Ratificação: aceitação formal dos atores } \\
\text { domésticos de cada Estado (quando previsto na } \\
\text { constituição do país). Momento de debate formal } \\
\text { e informal com atores governamentais e não } \\
\text { governamentais. }\end{array}$ \\
\hline $\begin{array}{l}\text { Governança do Regime: fase ligada a a } \\
\text { operacionalização e governança do regime. }\end{array}$ & $\begin{array}{l}\text { Rule-Making: fase de adequar a legislação interna } \\
\text { às mudanças necessárias para implementação } \\
\text { nacional do regime. Criação ou adaptação de } \\
\text { leis domésticas. Envolvimento de debate formal } \\
\text { e informal. Atores legislativos e dos grupos } \\
\text { interessados. }\end{array}$ \\
\hline $\begin{array}{l}\text { Ajustamento do Regime: alargamento ou } \\
\text { contração do regime. Fase em que se ajusta } \\
\text { o regime às novas demandas, informações, } \\
\text { questões problemas, entre outros itens que } \\
\text { flexibilizem o regime para as mudanças } \\
\text { necessárias. }\end{array}$ & $\begin{array}{l}\text { Enforcement, Monitoring and Reporting } \\
\text { Negotiations: mecanismos e negociações } \\
\text { relacionados à implementação dos novos } \\
\text { regulamentos e legislações. Mecanismos de } \\
\text { monitoramento, coerção e de distribuição e } \\
\text { produção de informação são usuais nesta fase. }\end{array}$ \\
\hline
\end{tabular}

Fonte: Adaptado de Spector (2003).

\section{O REGIME INTERNACIONAL DE MUDANÇAS CLIMÁTICAS}

Nos últimos anos, verificou-se o crescimento de um tema até então de pouca atenção entre as lideranças políticas: as mudanças climáticas e seus impactos nas condições gerais de sobrevivência no planeta. 0 aumento da presença de temas ambientais na pauta das discussões estatais desde Estocolmo ${ }^{7}$, o alerta da comunidade científica sobre as consequiências da ação antrópica sobre o planeta ${ }^{8}$, a organização da sociedade civil em torno do tema, assim como a evidência de fenômenos climáticos extremos como grandes inundações, secas, tsunamis, todos eles com grande potencial para a geração de conflitos, são alguns dos fatores que

\footnotetext{
${ }^{7}$ Conferência Internacional sobre Meio Ambiente Humano da ONU, realizada em 1972 na cidade de Estocolmo. Configura-se como a primeira grande conferência deste porte, que serviu de estímulo para discussões posteriores sobre questões ambientais e entrada definitiva da temática na agenda das relações internacionais.

${ }^{8}$ O IPCC - Painel Intergovernamental de Mudanças Climáticas da ONU representa uma importante fonte de dados e produção científica em torno do tema, principalmente com a divulgação final do relatório de 2007.
} 
informaram as iniciativas dos Estados para responder aos desafios de mitigar 0 processo das mudanças climáticas.

É a partir desta perspectiva que as negociações consubstanciadas na RIO $92^{9}$ sobre mudança do clima deram origem ao Regime Internacional de Mudanças Climáticas, cujo objetivo é promover a ação conjunta dos Estados no enfrentamento do aquecimento global, através de medidas de mitigação e adaptação às suas consequiências, já que o aumento da temperatura do planeta é fato observável, conforme alerta do meio científico.

Um dos maiores desafios desse Regime é a redução das emissões de Gases do Efeito Estufa (GEE). Esse desafio diz respeito à premente necessidade de realizar mudanças substantivas nas tecnologias em uso, bem como alterar as fontes de energias fósseis para outras renováveis e não poluentes.

A consideração dos fatores citados levou à criação da Convenção Quadro das Nações Unidas sobre Mudanças Climáticas (UNFCCC) ${ }^{10}$, aberta à assinatura dos Estados durante a RIO 92. A Convenção não estabeleceu metas, sendo sua criação um passo diplomático para futuras negociações. Com sua entrada em vigor em 1994, a convenção iniciou o processo de negociações em uma estrutura de conferências ${ }^{11}$ anuais entre as partes que funcionam como instância de negociação, regulamentação e ajustamento do regime. Tais reuniões, via Conferência das Partes (COP’s), configuram-se importantes espaços de negociação do regime, um ambiente de disputas de interesses entre os Estados ${ }^{12}$.

0 ano de 1997 marca uma importante fase do regime com a instituição do Protocolo de Quioto, que estabelece as diretrizes e os princípios que regem as metas do RIMC, sua governabilidade e implementação. Seu conteúdo prevê um ambicioso esforço das partes para evitar um agravamento maior das condições de vida no planeta, através do estabelecimento de metas obrigatórias para a redução

\footnotetext{
${ }^{9}$ Cúpula do Meio Ambiente e Desenvolvimento da ONU, também conhecida como RIO ou ECO 92, ocorrida na cidade do Rio de Janeiro em 1992. É considerada a maior conferência sobre o assunto, com 178 países representados (sendo que no período a ONU tinha 180 países membros). Para mais detalhes, em especial, sobre a atuação brasileira dentro da RI0-92, ver Lago (2007).

${ }^{10}$ Sigla em inglês da convenção.

${ }^{11}$ Até 0 momento ocorreram 15 Conferências das Partes (COP’s), sendo a última realizada dezembro de 2009 em Copenhague. Quando necessário, ocorrem reuniões ad hoc que preparam as partes para as COP's.

${ }^{12}$ Neste modelo o estado estabelece uma moldura normativa de direitos e deveres e deixa à conferência das partes, e a outras instâncias, o dever e o poder de pintar aquele quadro, ou seja, preencher aquele quadro sem sair da moldura (SOARES, 2002, p. 177).
} 
de GEE, assim como o desenvolvimento de tecnologia limpa, a cooperação entre as partes e outros mecanismos para enfrentar os efeitos do aquecimento global sem inibição do desenvolvimento econômico dos países, a exemplo do Mecanismo de Desenvolvimento Limpo (MDL).

Ponto polêmico e de constante divergência dentro do RIMC é a controvertida divisão entre os países, estabelecida pela criação do Anexo I, que reúne os países industrializados e os de economia em transição, notadamente os do Leste Europeu com metas obrigatórias de redução de GEE. Por outro lado, os países em desenvolvimento não tiveram metas obrigatórias estabelecidas, prevalecendo nas negociações o princípio das responsabilidades comuns, mas diferenciadas, que atribui responsabilidade histórica aos países desenvolvidos em função das emissões passadas, decorrentes do seu processo de industrialização ${ }^{13}$.

As tensões entre os grupos de interesses dentro do RIMC estão presentes desde o início das negociações que se prolongam há mais de uma década. Exemplo disto é a dificuldade da entrada em vigor do Protocolo de Quioto, já que os Estados Unidos, até então o maior emissor mundial de carbono na atmosfera ${ }^{14}$, não aceitou a diferenciação das responsabilidades ${ }^{15}$, impondo condições para sua assinatura ao protocolo e recusando-se a estabelecer quaisquer metas de redução enquanto as mesmas não forem estendidas a seus competidores comerciais, tal como a China. Por força dessas divergências, o Protocolo só entrou em vigor em 2005, com a assinatura da Federação Russa, o que possibilitou o cumprimento das exigências mínimas requeridas para a sua vigência.

O RIMC abarca a Convenção Quadro (UNFCCC), contando com um centro de pesquisas (IPCC), as COP's (incluindo suas reuniões preparatórias, as reuniões dos Grupos Ad Hoc e dos órgãos subsidiários), além do Protocolo de Quioto. Em 2009 registram-se mais de 170 países envolvidos nas negociações.

\footnotetext{
${ }^{13}$ Algumas críticas à defesa de tal princípio e perigo deste aos objetivos comuns do regime podem ser vistas em Viola, Barros-Platiau e Leis (2008).

${ }^{14}$ Em 2006 a China ultrapassou os EUA, tornando-se responsável, neste ano, pela emissão de 5,7 bilhões de tonelada de carbono contra 5,6 bilhões dos EUA.

${ }^{15} 0$ Senado norte-americano proibiu o Executivo de ratificar o Protocolo de Quioto, apesar de 0 governo Clinton ter expressado intenção de adesão ao assiná-lo. Portanto, o compromisso não é vinculativo para os EUA. Cabe ressaltar que durante o governo que o sucedeu, com George W. Bush à frente, houve um retrocesso em relação ao maior envolvimento dos Estados Unidos nas negociações. As expectativas recaem agora sobre atual governo norte-americano, liderado por Barack Obama.
} 
0 RIMC busca se organizar de forma a lidar com tais questões em consideração às demandas e interesses políticos dos Estados. A diversidade de interesses e o embate político nas arenas de negociação do regime têm retardado a adoção de soluções para o enfrentamento do problema. Isto se reflete diretamente nas deliberações do regime, assim como nas dificuldades de implementação. Entretanto, o RIMC representa um importante ponto de apoio institucional a uma temática ligada de forma crescente às questões de segurança: a questão energética.

\section{MudAnÇAS ClimátiCAS E SEGURANÇA ENERGÉTICA}

Ao longo de sua evolução, o planeta Terra passou por mudanças do padrão climático em diversos momentos. Apesar de esperada, a alteração do clima global vem suscitando preocupações crescentes em vários setores da sociedade, perpassando por lideranças políticas, acadêmicos, ambientalistas, empresários e movimentos sociais. Tal preocupação se deve ao fato de que a mudança do clima vem ocorrendo de forma acelerada, intensa e prejudicial à sobrevivência das espécies no planeta. Suas conseqüências estão cada vez mais visíveis, alterando os padrões climáticos esperados em todo o globo.

Pesquisas científicas, em especial as apresentadas no âmbito dos relatórios do IPCC, indicam a elevação da temperatura do planeta provocada pelo aumento do efeito estufa ${ }^{16}$. A alteração climática em desenvolvimento demanda ações emergenciais de mitigação, a fim de se evitar conseqüências futuras que representem ameaças inevitáveis à sobrevivência humana ${ }^{17}$.

Estudos científicos sobre a aceleração da mudança climática indicam que estase relaciona estreitamente àsfontesdeenergiaprevalecentes no desenvolvimento industrial ${ }^{18}$ desde seus primórdios. A exploração dos recursos energéticos fósseis

${ }^{16} 0$ efeito estufa é um fenômeno natural responsável pelo equilíbrio térmico do planeta e intensificado em função da acumulação de gases poluentes (GEE).

${ }^{17}$ A manutenção da estabilidade relativa do clima global, por meio da mitigação de seus impactos e da adaptação da sociedade internacional e nacional às novas condições globais (mais quentes e mais sujeitas à incidência de fenômenos climáticos extremos) coloca as mudanças climáticas no âmbito das preocupações de segurança internacional, levando à ideia de segurança climática. "A segurança climática implica uma clara escolha da humanidade pela prioridade da mitigação do aquecimento global sobre a adaptação [...] segurança climática coloca-se num novo patamar em comparação com a ameaça mais profunda experimentada previamente pela humanidade: 0 risco de uma guerra nuclear durante a guerra fria [...] a segurança se correlaciona com uma forte governança global do aquecimento global [...]" (VIOLA; BARROS-PLATIAU; LEIS, 2008, p. 8).

${ }^{18}$ Ver relatórios do IPCC. 
e sua utilização contribuíram significativamente para o acúmulo de Gases do Efeito Estufa (GEE) ${ }^{19}$ na atmosfera, tendo como consequiência a intensificação do aquecimento global2 ${ }^{20}$. A emissão dos GEE a partir dos insumos energéticos se dá pela queima de materiais como carvão, petróleo, lenha, xisto, gás natural, dentre outros.

As atividades humanas de impacto prejudicial no clima global aumentaram significativamente com o processo de urbanização e industrialização. Neste sentido, os cenários de emissão projetados pelo IPCC levam em conta fatores tal como o tamanho da população, padrões de consumo, a utilização de combustíveis fósseis e a eficiência energética.

As medidas direcionadas à segurança energética dos países devem levar em conta, nesse contexto, as preocupações com as emissões de gases poluentes pela utilização dos recursos de energia, o impacto das mudanças climáticas sobre a infra-estrutura do setor e a eficiência energética. 0 investimento em fontes renováveis, sustentáveis e limpas na matriz energética tem sido recomendado como alternativa aos insumos fósseis e poluentes de ampla utilização. Entretanto, algumas considerações sobre o impacto da mudança do clima em relação a tais fontes devem ser feitas.

Dentre os recursos alternativos mais cogitados para composição progressiva na matriz energética em todo o globo temos o investimento no insumo hídrico como força motriz para produção de energia elétrica; a utilização de oleaginosas ${ }^{21}$, cana-de-açuçar e outros insumos vegetais como biocombustíveis; o uso da energia solar, eólica e até nuclear. 0 gás natural tem adquirido papel de relevo, mesmo se originando de fonte fóssil. A maioria das opções acima está sujeita aos impactos climáticos, assim como nem todas não estão isentas de contribuir com efeitos nocivos sobre o clima.

Sobre os impactos climáticos, pode-se dizer que alterações na cobertura vegetal, no nível pluviométrico, na temperatura, na umidade, assim como

\footnotetext{
${ }^{19}$ A liberação de GEE pelas atividades humanas, ao se dar de modo descontrolado, promove 0 aquecimento do planeta em condições prejudiciais à qualidade de vida terrestre.

${ }^{20} 0$ quarto relatório do IPCC, divulgado em 2007, chama o fenômeno atual do aquecimento global como "inequívoco", considerando que "muito provavelmente" as principais causas desse aquecimento são as emissões de gases por indústrias e veículos.

${ }_{21}$ "São plantas vegetais que possuem óleos e gorduras que podem ser extraídos através de processos adequados. Os óleos extraídos são substâncias insolúveis em água (hidrofóbicas), que na temperatura de $20^{\circ} \mathrm{C}$ exibem aspecto líquido" (OLEAGINOSAS..., 2009).
} 
o surgimento ou intensificação de fenômenos climáticos ${ }^{22}$ em todo o globo, produzem reflexos no acesso, distribuição e na eficiência dos insumos energéticos citados. A alteração da velocidade do vento influi sobre a produção de energia eólica. Mudanças no regime de chuvas afetam o funcionamento das hidrelétricas e seu fornecimento energético. Transformação na cobertura vegetal e o índice de precipitação são fatores que influem sobre a distribuição geográfica do cultivo da cana-de-açúcar e oleaginosas. Nem a produção de termeletricidade a gás natural escapa, sendo observável que as turbinas de gás reagem às alterações no ambiente de temperatura e umidade (SCHAEFFER et al, 2008).

Quadro 2 - Segurança Energética e Mudanças Climáticas

\begin{tabular}{|l|l|}
\hline \multicolumn{1}{|c|}{ Perguntas } & \multicolumn{1}{c|}{ Respostas } \\
\hline $\begin{array}{l}\text { Qual o problema central } \\
\text { das mudanças climáticas } \\
\text { na atualidade? }\end{array}$ & $\begin{array}{l}\text { 0 aumento do efeito estufa que contribui para o desequilíbrio } \\
\text { térmico do planeta. }\end{array}$ \\
\hline Como isto ocorre? & Com o aumento das emissões de GEE. \\
\hline $\begin{array}{l}\text { O que tem provocado tal } \\
\text { aceleração? }\end{array}$ & $\begin{array}{l}\text { As atividades humanas que resultem em emissões de GEE na } \\
\text { atmosfera em larga escala. }\end{array}$ \\
\hline $\begin{array}{l}\text { Qual a relação do do } \\
\text { aquecimento global com as } \\
\text { questões energéticas? }\end{array}$ & $\begin{array}{l}\text { A utilização constante e em grande quantidade de fontes de } \\
\text { energia nocivas à atmosfera por sua emissão de gases poluentes. }\end{array}$ \\
\hline $\begin{array}{l}\text { Qual o desafio para o setor } \\
\text { energético? }\end{array}$ & $\begin{array}{l}\text { Corte nas emissões de GEE, em especial o carbono, sem } \\
\text { prejudicar o desenvolvimento almejado pelos Estados e demais } \\
\text { atores de interesse. }\end{array}$ \\
\hline $\begin{array}{l}\text { Qual o foco da segurança } \\
\text { energética a partir deste } \\
\text { desafio? }\end{array}$ & $\begin{array}{l}\text { Promover medidas de eficiência energética em conjunto com } \\
\text { o corte das emissões e à promoção do desenvolvimento (sob o } \\
\text { enfoque sustentável) para contribuir na mitigação dos efeitos da } \\
\text { mudança do clima. }\end{array}$ \\
\hline
\end{tabular}

Fonte: Autora

Pelo quadro acima e por todo o exposto é possível perceber como as temáticas se interligam, sendo necessário repensar políticas tanto para mitigar e promover a adaptação às mudanças do clima, quanto para garantir a segurança

${ }^{22} \mathrm{Tal}$ como enchentes, tufões, maremotos, terremotos. 
energética de modo sustentável e harmônico com o meio ambiente. Lidar com a nova realidade que se configura diante da alteração climática mundial e da demanda de expansão crescente de desenvolvimento é o desafio colocado às lideranças políticas em todo o globo quando da formulação e tomada de decisão em políticas de segurança energética.

Por fim, cabe ressaltar que a consideração sobre a relação entre clima e energia requer presença tanto nas discussões e políticas de cooperação no ambiente internacional como no ambiente doméstico de cada país, permitindo resultados mais satisfatórios frente aos desafios impostos.

\section{REGIME DE MUDANÇAS CLIMÁTICAS E ENERGIA}

No âmbito das mudanças climáticas, o RIMC busca lidar com o fato de que os países industrializados são os principais emissores dos GEE, e suas economias se encontram enraizadas num modelo de consumo cíclico auto-destrutivo, que demanda mudanças emergenciais (FEITOSA, 2009; FUSER, 2008; LISBOA, 2009; SOARES, 2003; VIOLA, 2009). Dentre os países do Anexo I do Protocolo de Quioto, as emissões via setor energético correspondem a mais de 80\% em relação aos demais setores. Dentro destas emissões, cabe ressaltar que a grande maioria se dá pelo uso de recursos combustíveis, mas inclui também as emissões de gases através do processo que envolve a produção, o processamento, a transmissão, a estocagem e o uso de combustíveis. Outro importante dado é que das $83 \%$ das emissões de origem no setor energético, 94\% correspondem ao $\mathrm{CO}_{2}, 5 \%$ de $\mathrm{CH}_{4}$ e $1 \%$ de $\mathrm{N}_{2} \mathrm{O}$ (INTERNATIONAL ENERGY AGENCY, 2009).

Vale lembrar ainda que mesmo as fontes de energia consideradas limpas podem provocar efeitos nocivos ao meio social e ambiental. Isto porque a possibilidade de custos e impacto nulo é pouco provável uma vez que mesmo aquelas que não emitem GEE têm algum tipo de contrapartida. Este é o caso da energia nuclear que, se por um lado é considerada uma fonte limpa por não emitir nenhum tipo de GEE, por outro incorpora riscos de acidente radioativo de forte impacto sobre o meio ${ }^{23}$, além de gerar problemas quanto à destinação dos resíduos

\footnotetext{
${ }^{23}$ Acidentes nucleares como os de Chernobyl (1986), Three Mile Island (1979) e Tokaimura (1999) reforçam as apreensões quanto ao uso de urânio para a geração de energia e para o desenvolvimento tecnológico, diante dos impactos radioativos na sociedade e no meio ambiente. No Brasil, a violação de uma cápsula de césio 137 utilizada em um aparelho hospitalar de radioterapia provocou na cidade de Goiânia, no ano de 1987, um grave acidente no qual 621 pessoas foram contaminadas, quatro pessoas foram mortas, além de produzir cerca de seis mil toneladas de lixo radioativo.
} 
tóxicos. As hidrelétricas, por sua vez, quando dissociadas de um planejamento eficiente dos impactos ambientais e sociais ${ }^{24}$ de suas construções, podem gerar a liberação de GEE por dezenas de anos, devido ao processo de decomposição da vegetação de áreas alagadas.

Em relação à eficiência, o uso de alguns recursos alternativos deixa a desejar. Além de demandar o investimento em tecnologia de ponta para aproveitamento de determinados recursos, a sua produção na quantidade e no tempo desejado depende das dinâmicas naturais. 0 uso da energia solar exige a exposição satisfatória a esta fonte e de tecnologia para captar e armazenar. Já a energia eólica depende da velocidade dos ventos para atuar como força motriz, o que pode variar muito de região para região, do período do ano, de horário e até das alterações climáticas atuais. Neste caso, a produção eólica satisfatória pode não coincidir com os horários de pico em que a demanda é maior, podendo gerar insuficiência na produção e fornecimento energético.

Esses são alguns dos desafios pertinentes às preocupações quanto à segurança energética que perpassam as negociações no âmbito do regime. 0 acordo inicial que busca fazer frente a tais desafios e implementar o objetivo da UNFCCC $^{25}$ é 0 Protocolo de Quioto ${ }^{26}$. 0 documento incentiva a cooperação técnica, 0 investimento em tecnologias, assim como a alteração da matriz energética fóssil dos países membros e metas de redução das emissões de gases poluentes para os países listados no Anexo I. Todos esses recursos são levantados com o objetivo de desacelerar o aquecimento do planeta a partir da redução das emissões dos GEE. Entretanto, alguns pontos obstruem o sucesso da implementação do acordo, dificultando a governança do regime e promovendo sucessivas tentativas de ajustes a fim de garantir que seja atingido o fim para o qual foi criado.

Este processo de operacionalização do regime enfrentou obstáculos desde o início. Apesar de disponibilizado para assinatura já em 1997 na COP 3, 0 protocolo ${ }^{27}$ só entrou em vigor no ano de 2005. Ao analisar o período de 1992 a

\footnotetext{
${ }^{24}$ A derrubada da vegetação nativa e o deslocamento populacional são aspectos envolvidos na construção de hidrelétricas que devem ser avaliados.

${ }^{25}$ Qual seja "estabilizar as concentrações de gases de efeito estufa na atmosfera em níveis seguros".

${ }^{26} 0$ Protocolo de Quioto estabelece regras gerais de redução, mas sem definir como se atingir as metas propostas.

${ }^{27}$ Somente na COP 4 em 1998 é que as atenções nas negociações se voltaram para a implementação do protocolo. Após três anos de discussões é que se chegou a um consenso quanto às regras e procedimentos para implementação do Protocolo de Quioto e seus mecanismos de flexibilização
} 
2002, o Secretário Executivo da UNFCCC relatou que a atenção das negociações estava na busca de consenso sobre regras de implementação, e que somente a partir de então é que o foco estaria voltado para a aplicação das regras estabelecidas e elevação da importância da questão climática nas políticas públicas nacionais e no envolvimento de atores domésticos ${ }^{28}$. Mesmo após a entrada em vigor, grande parte dos países com metas obrigatórias de redução não haviam colocado em prática medidas para atingir o objetivo proposto, ou pelo menos, não estavam se comprometendo com o percentual definido de redução. 0 argumento principal se centrava em torno do princípio da responsabilidade comum, mas diferenciada que, segundo os países desenvolvidos, não se mostrava eficiente, já que os países em desenvolvimento estão em processo de industrialização e, portanto, contribuindo para a poluição e aquecimento do planeta. Isto seria motivo para que os países fora do Anexo I também tivessem que se comprometer obrigatoriamente com metas de redução.

Os países em desenvolvimento, por seu turno, alegam que suas contribuições para a mudança climática do planeta são recentes e, portanto, não são responsáveis pelo nível atual de aceleração do efeito estufa, já que este é consequiência do acúmulo de gases na atmosfera, que ocorreu ao longo dos anos do processo de industrialização. Argumentam também que os países industrializados, por terem maiores condições financeiras e tecnológicas (além de maior responsabilidade histórica na mudança do clima) devem fornecer meios de apoiar o desenvolvimento com base sustentável para aqueles que se encontram em processo tardio de industrialização. Isso se daria através da transferência de tecnologias, apoios técnicos, transferências de recursos, dando meios financeiros de desenvolvimento, além das metas obrigatórias continuarem, neste momento, centradas ainda nos países do Anexo I.

Uma saída para essa tensão foi o advento do Mecanismo de Desenvolvimento Limpo (MDL), estabelecido no artigo 12 do Protocolo de Quioto, com o objetivo de ajudar os países desenvolvidos (Anexo I) a atingir suas metas de redução de emissão e promover o desenvolvimento sustentável nos países em desenvolvimento. Com o MDL os países do Anexo I podem gerar ou comprar reduções certificadas de emissão de projetos desenvolvidos em países fora do Anexo I. Em contrapartida, estes países têm acesso a recursos financeiros e tecnologias limpas. Os projetos de

no que ficou conhecido como Acordo de Marrakesh (COP 7).

${ }^{28}$ Ver site do Conselho Empresarial Brasileiro para o Desenvolvimento Sustentável. http://www. cebds.org.br/cebds/mc-convencao-clima.asp. 
MDL podem se basear na conservação e eficiência de energia, em fontes renováveis e alternativas energéticas ou no reflorestamento. 0 foco de tais projetos é a redução das emissões de $\mathrm{GEE}^{29}$ ou captura (seqüestro) de carbono.

0 incentivo a projetos de MDL não diluí a tensão. A dificuldade de implementação do protocolo por parte dos países membros continuou, o que demandou um ajustamento do regime. É neste ponto que as discussões se voltaram para o estabelecimento de um novo acordo para o período subseqüente ao fim da vigência do Protocolo de Quioto. Considerando que o protocolo estabelecia a obrigatoriedade de redução em 5,2\% das emissões em relação aos níveis de 1990, apenas para o período de 2008 a 2012, o documento ficou conhecido como primeiro período de compromissos. A partir da COP 13 em Bali (2007), iniciaramse os preparativos para a promoção de um novo acordo sobre o clima, que deveria ser concretizado na COP 15 em dezembro de 2009.

0 novo acordo deveria propor metas mais ousadas para fazer frente aos riscos climáticos do aumento de temperatura em médio prazo, conforme divulgado em 2007 pelo IPCC. Deveria também chegar a um consenso quanto à participação dos membros na consecução dos objetivos propostos pelo regime. As COP 13 e 14 foram consideradas conferências preparatórias para o encontro em Copenhague (COP 15). Em novembro de 2007, o relatório divulgado pelo IPCC propõe um corte entre 25\% a 40\% das emissões em médio prazo em relação aos níveis de 1990. Tanto em Bali, na COP 13, como na COP 14 realizada em Poznan, em 2008, a faixa de corte de emissões proposta até 2050 se manteve, assim como as atenções para medidas de mitigação e adaptação à alteração climática. Essas duas reuniões vêem frustradas todas as expectativas com a realização da COP 15 que, após uma semana de tensões, chegou ao final sem consenso e sem acordo. Uma carta de intenções e outros documentos não vinculativos foram os materiais produzidos, sem metas definidas. Apesar da menção de ajuda financeira aos países menos industrializados cabe ressaltar que até 2011 não houve nenhum compromisso concreto definido, sendo previsto um plano nacional de intenções a ser entregue por cada país membro. A COP 16 também não produziu os resultados esperados, deixando pendente a realização de um acordo substitutivo ao Protocolo de Quioto, que deveria entrar em vigor em 2012.

${ }^{29}$ Os projetos deverão resultar em reduções reais, mensuráveis e de longo prazo. 
Em linhas gerais, pode-se visualizar as fases do Regime de Mudanças Climáticas e seu processo de implementação no nível internacional da seguinte maneira:

Quadro 3 - Fases do Plano Internacional do RIMC.

\begin{tabular}{|c|c|}
\hline Plano & Internacional \\
\hline $\begin{array}{l}\text { Formação do } \\
\text { RIMC }\end{array}$ & $\begin{array}{l}\text { - Criação da UNFCCC em 1992; } \\
\text { - COP’́s como instâncias máximas de deliberação; } \\
\text { - COP } 1 \text { a 3: formação do regime, definição de princípios e busca por um } \\
\text { acordo inicial. }\end{array}$ \\
\hline $\begin{array}{l}\text { Governança } \\
\text { do regime }\end{array}$ & $\begin{array}{l}\text { - COP } 3 \text { e Protocolo de Quioto; } \\
\text { - COP } 4 \text { a COP 12: primeiro momento: negociação das regras e mecanismos } \\
\text { de flexibilização. Segundo momento: atenção sobre a implementação do } \\
\text { Protocolo de Quioto. } \\
\text { - Estímulo a projetos de MDL; } \\
\text { - Estímulo e metas obrigatórias para cortes de emissões de GEE e substituição } \\
\text { da matriz energética fóssil; } \\
\text { - Estímulo a transferência de tecnologia e de recursos aos países em } \\
\text { - } \text { desenvolvimento; } \\
\text { - Pouco em torno da obrigatoriedade de metas; }\end{array}$ \\
\hline $\begin{array}{l}\text { Ajuste do } \\
\text { regime }\end{array}$ & $\begin{array}{l}\text { - COP } 13 \text { e 14: reuniões preparatórias em busca de um novo acordo; } \\
\text { - Pressão para que os países "Não-Anexo I" assumam metas obrigatórias; } \\
\text { - COP } 15 \text { e 16: ausência de um acordo substitutivo ao Protocolo de Quioto; }\end{array}$ \\
\hline
\end{tabular}

Fonte: Autora

\section{ConsideraÇõES FINAIS}

Aabrangênciae temática do Regime Internacional de Mudanças Climáticas, por si só, implicam a atenção sobre a questão energética nas negociações, já que os impactos e as saídas mitigatórias e adaptativas ao problema das alterações do clima global na contemporaneidade estão intimamente ligados ao uso e distribuição das fontes energéticas. A importância do Regime também é visivel ao se perceber que como um fórum institucional de cooperação, envolvendo os atores estatais, suas normas, diretrizes e regulações, visa ser implementado no ambiente doméstico dos Estados para a consecução das metas previstas. Deste modo, o RIMC visa atuar 
sobre o comportamento dos atores tanto estatais como não estatais, ao envolver em seu processo de implementação doméstica toda a sociedade. Observamos que o momento pelo qual perpassa a dinâmica atual do RIMC é de ajustamento e, por tanto, um processo delicado que tende aliar os interesses próprios dos atores estatais envolvidos com a demanda de resolução doméstica e internacional crescente com o agravamento dos impactos das alterações climáticas e das tensões sobre interesses energéticos.

Por fim, cabe aos analistas internacionais, sociedade civil e autoridades atentarem para a complexidade envolvida nas negociações internacionais sobre 0 clima em relação às questões de segurança energética, mas também estimularem o debate e ações concretas para a consolidação de propostas cooperativas e medidas de implementação que, apesar da urgência, devem ser flexíveis para atender ao contexto e as realidades de cada local.

\section{REFERÊNCIAS}

FEITOSA, Vitor. A revolução necessária. Jornal Estado de Minas, Belo Horizonte, 14 nov. 2009. Caderno Pensar Brasil: Dossiê Ecologia

FUSER, Igor. Petróleo e poder: o envolvimento militar dos Estados Unidos no Golfo Pérsico. São Paulo: Ed. UNESP, 2008.

INTERGOVERNAMENTAL PANEL OF CLIMATE CHANGE - IPCC. Summary for policymakers. 2007. Disponível em: <http://www.ipcc.ch/pdf/assessment-report/ ar4/syr/ar4_syr_spm.pdf> Acesso em: 14 maio 2009.

INTERNATIONAL ENERGY AGENCY. IEA Statistics: $\mathrm{CO}_{2}$ emissions from fuel combustion. França: OECD/IEA, 2009.

KEOHANE, Robert 0. International institutions and state power. Boulder: Westview Press, 1989.

After hegemony: cooperation and discord in the world economy. Princeton, NJ: Princeton University Press, 1984.

KRASNER, Stephen (Ed.). International regimes. Ithaca: Cornell University Press, 1983.

LAG0, André Aranha Corrêa do. Estocolmo, Rio e Joanesburgo: o Brasil e as três conferências ambientais das Nações Unidas. Brasília: IRBr, FUNAG, 2007.

LISBOA, Apolo H. Sabedoria das águas. Jornal Estado de Minas, Belo Horizonte, 14 nov. 2009. Caderno Pensar Brasil: Dossiê Ecologia. 
OLEAGINOSAS. Disponível em: <http://www.setor1.com.br/oleos/oleagi_ no.htm>. Acesso em: 14 maio 2009.

SCHAEFFER, Roberto et al.. Mudanças Climáticas e Segurança Energética no Brasil. Rio de Janeiro: COPPE, 2008.

SOARES, Guido Fernando Silva. Direito internacional do meio ambiente: emergência, obrigações e responsabilidades. 2. ed. São Paulo: Atlas, 2003. . Um desafio ao entendimento. In: PHILLIPPI JUNIOR, Arlindo et al. (Ed.). Meio ambiente, direito e cidadania. São Paulo: Signus, 2002. p. 175-181. SPECTOR, Bertran I. Desconstruting the negotiations of regimes dynamics. In: ZARTMAN, J. William (Ed). Getting it done: post-agreement negotiation and intenational regimes. Washington, DC: United States Institute of Peace Press, 2003. VIOLA, Eduardo. Os grandes emissores de carbono e as perspectivas de um acordo para mitigar a mudança climática. In: NASSER, Reginaldo M. (Org.). Os conflitos internacionais em múltiplas dimensões. São Paulo: Ed. UNESP, 2009. p. 131146.

VIOLA, Eduardo; BARROS-PLATIAU, Ana Flavia; LEIS, Hector Ricardo. Governança e segurança climática na América do Sul. São Paulo: IFHC; Santiago: CEPLAN, 2008.

YOUNG, Oran R. International governance: protecting the environment in a stateless society. London: Cornell University Press, 1994.

ZARTMAN, J. William (Ed). Getting it done: post-agreement negotiation and intenational regimes. Washington, DC: United States Institute of Peace Press, 2003. 